\title{
A specific mixture of short-chain galacto-oligosaccharides and long-chain fructo-oligosaccharides induced an anti-allergic Ig profile in infants at risk for allergy
}

\author{
A. J. Nauta ${ }^{1}$, S. Arsnalognu ${ }^{2}$, G. Boehm ${ }^{3}$, G. Moro ${ }^{2}$, J. Faber ${ }^{1}$, E. Knol ${ }^{1}$, B. Ruiter ${ }^{4}$, \\ E. van Hoffen ${ }^{4}$, L. M'Rabet ${ }^{5}$ and J. Garssen ${ }^{1,2}$ \\ ${ }^{1}$ Immunology, Numico-Research BV, Wageningen, The Netherlands, ${ }^{2}$ Macedonio Melloni Maternity Hospital, Center for \\ Infant Nutrition, Milano, Italy, ${ }^{3}$ Numico-Research, Friedrichsdorf, Germany, ${ }^{4}$ Academic Hospital Utrecht, Dermatology, \\ Utrecht, The Netherlands and ${ }^{5}$ Utrecht Institute for Pharmaceutical Sciences, Pharmacology and Pathophysiology, \\ Utrecht, The Netherlands
}

In a prospective study in infants with a family history of atopy a specific prebiotic oligosaccharide mixture (90\% short-chain galactooligosaccharides and 10\% long-chain fructo-oligosaccharides (GOS/FOS; IMMUNOFORTIS) reduced the cumulative incidence of atopic dermatitis at 6 months of age ${ }^{(1)}$. In a subgroup of these infants $(n 84)$ it was possible to obtain a blood sample at 6 months of age to analyse the potential effect of these dietary oligosaccharides on the Ig profile.

In this prospective double-blind randomized placebo-controlled study the infants received a hypoallergenic formula with either $8 \mathrm{~g}$ GOS/FOS/l or $8 \mathrm{~g} /$ maltodextrin (placebo)/l for 6 months. At 3 months of age children were vaccinated against diphtheria, tetanus and polio (DTP). At 6 months of age total plasma levels of IgE, IgG1, IgG2, IgG3 and IgG4 as well as cow's-milk protein (CMP)- and DTPspecific Ig were measured by ELISA.

Supplementation with GOS/FOS led to a significant reduction in plasma levels of total $\operatorname{IgE}(P=0.007), \operatorname{IgG} 2(P=0.029)$ and $\operatorname{IgG} 3$ $(P=0.0343)$ whereas no significant effect on IgG4 was observed. The plasma levels of CMP-specific IgG1 was significantly decreased $(P=0.015)$ in the GOS/FOS group. The levels of CMP-specific IgE were very low and no effect of GOS/FOS supplementation was observed. CMP-specific IgG4 was not detectable in the samples. No effect of GOS/FOS supplementation on any vaccine-specific antibody isotype levels was found.

Evidently, GOS/FOS supplementation induced an anti-allergic Ig profile in infants at high risk for allergic diseases while the desired specific immune responses were unaffected, indicating the potential role of oral GOS/FOS exposure for primary prevention of allergies.

\begin{tabular}{lccc}
\hline & Placebo $($ median$)$ & GOS/FOS $($ median $)$ & $P$ \\
\hline Total IgE $(\mathrm{kU} / \mathrm{ml})$ & 10.0 & 4.00 & 0.008 \\
Total IgG1 $(\mathrm{g} / \mathrm{L})$ & 3.09 & 2.26 & 0.005 \\
Total IgG4 $(\mu \mathrm{g} / \mathrm{L})$ & 187.7 & 427.2 & 0.728 \\
CMP IgE $(\mathrm{ng} / \mathrm{ml})$ & 2.50 & 1.80 & 0.348 \\
CMP IgG1 $(\mathrm{AU} / \mathrm{ml})$ & 3.40 & 1.00 & 0.015 \\
DTP IgE $(\mathrm{AU} / \mathrm{ml})$ & 0.40 & 0.37 & 0.884 \\
DTP IgG1 $(\mathrm{AU} / \mathrm{ml})$ & 441.3 & 329.6 & 0.748 \\
\hline
\end{tabular}

1. Moro G, Arslanoglu S, Stahl B, Jelinek J, Wahn U \& Boehm G (2006) Arch Dis Child 91, 814-819. 